\title{
Clamp-Crush Technique for Laparoscopic Liver Resection
}

\author{
Takeo Nomi, MD, PhD, Daisuke Hokuto, MD, PhD, Takahiro Yoshikawa, MD, PhD, Naoki Kamitani, MD, \\ Yasuko Matsuo, MD, and Masayuki Sho, MD, PhD
}

Department of Surgery, Nara Medical University, Nara, Japan

\begin{abstract}
Liver parenchymal transection is the most important process in laparoscopic liver resection (LLR). Various surgical methods and devices for LLR have been applied including the cavitron ultrasonic surgical aspirator, ultrasonic scalpel, and staplers. Very few reports have investigated the clamp-crush technique for LLR. ${ }^{1,2}$ Current study shows a clamp-crush technique for LLR and evaluates its perioperative outcomes. The clamp-crush technique was performed using simple forceps and the Pringle maneuver under a low central venous pressure. The vessels that remained after crushing were clipped if they were thick; or removed with an ultrasonic cutting-coagulation system if they were thin. Sixty-one LLRs were performed using the clamp-crush technique. Pathological cirrhosis was observed in 22 patients $(36.0 \%)$. The types of resection were as follows: 31 wedge resections $(50.8 \%), 11$ segmentectomies (19.0\%), 9 sectionectomies (14.8\%), and 10 hemihepatectomies (16.4\%). The intraoperative blood loss was $62 \mathrm{ml}$; the surgical duration was $272 \mathrm{~min}$. The postoperative major complication (Clavien-Dindo $\geq$ IIIa) rate was $4.9 \%$. The median hospital stay was 8 days (range $=4-53$ days). A 76-year-old female underwent right LLR for a 9-cm HCC. The right hepatic artery and portal vein were dissected separately. After mobilizing the liver, parenchymal transection was performed using the clamp-crush
\end{abstract}

technique. The middle hepatic vein was totally exposed. Intraoperative blood loss was $32 \mathrm{ml}$ and the surgical duration was $5 \mathrm{~h} 32 \mathrm{~min}$ with no postoperative complications. The clamp-crush technique is safe and feasible for LLR and could contribute to quick parenchymal transection and flattening of the transection plane.

DISCLOSURES Takeo Nomi, Daisuke Hokuto, Takahiro Yoshikawa, Naoki Kamitani, Yasuko Matsuo, Masayuki Sho have no conflicts of interest to declare.

\section{REFERENCES}

1. Otsuka Y, Kaneko H, Cleary SP, Buell JF, Cai X, Wakabayashi G. What is the best technique in parenchymal transection in laparoscopic liver resection? Comprehensive review for the clinical question on the 2nd International Consensus Conference on Laparoscopic Liver Resection. J Hepatobiliary Pancreat Sci. 2015;22:363-370.

2. Uchiyama H, Itoh S, Higashi T, Korenaga D, Takenaka K. Pure laparoscopic partial hepatectomy using a newly developed vessel sealing device, BiClamp. Surg Laparosc Endosc Percutan Tech. 2013;23:e116-e118.

Publisher's Note Springer Nature remains neutral with regard to jurisdictional claims in published maps and institutional affiliations.
Electronic supplementary material The online version of this article (https://doi.org/10.1245/s10434-020-08822-x) contains supplementary material, which is available to authorized users.
(C) Society of Surgical Oncology 2020

First Received: 23 April 2020

Accepted: 20 June 2020;

Published Online: 13 July 2020

T. Nomi, MD, PhD

e-mail: nomi@naramed-u.ac.jp 